\title{
The identification of two Algerian Arabic dialects by prosodic focus
}

\author{
Ismaël Benali \\ CLILIAC-ARP, Université Paris Diderot, France \\ https://doi.org/10.36505/ExLing-2016/07/0006/000265
}

\begin{abstract}
The purpose of this research is to show that it is easier to identify the prosody of Algiers and Oran dialects when a focus is produced. For this study, we compared prosodic features associated with different types of focus: broad focus, emphatic narrow focus, contrastive narrow focus and interrogative focus. It appears from the acoustical analysis that recurrences of prosodic patterns that differentiate the two dialects were observed in narrow and interrogative focus. The analysis of the interaction between the identification of the two dialects and the four types of focus showed that Algiers and Oran speakers are better identified when their utterances are produced with narrow focus when it is placed at the edge of an intonation phrase and interrogative focus.
\end{abstract}

Key words: dialectal variations, Algerian Arabic, intonation, focus

\section{Introduction}

Several studies have shown that dialectal varieties can be differentiated only on the basis of prosody. The suprasegmental parameters such as speech rate, F0 register and range, F0 excursion and F0 alignment are sufficient to distinguish and identify dialects.

The Algiers and Oran varieties are two urban dialects of Algeria. They are characterized by regional accents marked segmentally and prosodically.

In a previous studies (Benali, 2004), it appeared that Algiers speakers produced more melodic variations than Oran speakers who tended to produce more syllabic lengthening. We found also that intonation patterns which characterize Algiers and Oran varieties are marked more clearly when the speaker spoke with emphasis and implication. To study this phenomenon, we compared prosodic features (mainly F0 movements) associated with different types of focus: first, broad focus (emphasis on the whole or a part of utterance); then, emphatic narrow focus (strong emphasis on a specific item of an utterance); then, contrastive narrow focus (emphasis on a contrasting item in an utterance) and finally, interrogative focus (emphasis of a linguistic element on which the question bears).

In most languages, narrow focus is marked by F0 rise and often accompanied by an increase of duration and intensity (Hirst and Di

ExLing 2016: Proceedings of 7th Tutorial and Research Workshop on Experimental Linguistics, 27 June - 2 July 2016, Saint Petersburg, Russia 
Cristo, 1998). In a comparison of the acoustic realizations of contrastive focus carried on three Arabic dialects: Moroccan Arabic, Kuwaiti Arabic and Yemeni Arabic, Yeou and al (Yeou et al., 2007) have shown that these dialects share the same strategy in the realization of contrastive focus consisting in a rising falling movement. This melodic contour was more locally defined in Yemeni and Kuwaiti Arabic while it may span the entire focused word in Moroccan Arabic. Moroccan Arabic is distinguished by a significant effect of the syllabic structure on F0 peak alignment: It occurs within the accented syllable when it is closed and outside when it is open. In Kuwaiti and Yemeni Arabic, this peak occurs within but near the end of the accented vowel either in open or closed syllable. In Egyptian Arabic, S. Hellmuth (Hellmuth, 2011) showed an increase of $\mathrm{FO}$ in focus and a compression of it in the following words. Also in Tunisian Arabic (Bouchhioua, 2009), focus affects positively the duration of both the stressed syllable and the unstressed syllable. Stressed final syllables are more lengthened and the F0 and intensity of the stressed syllable increase in effect of focus.

\section{Methodology}

20 Algiers speakers (15 men and 5 women) and 20 Oran speakers (10 men and 10 women) were recorded in their respective cities. There is spontaneous and read speech. Focus was either naturally produced or provoked. In a first experiment we isolated the prosodic information, using a method of delexicalization by filtering speech frequency above $400 \mathrm{~Hz}$. In a second experiment we manipulated non filtered speech: we transposed F0 variations and vowels durations of the read statements of one dialect onto the other and vice versa. We submitted these two types of stimuli to 30 listeners (neither from Algiers nor from Oran) who had to identify the dialects.

The analysis and the acoustic manipulations were carried either on the speech analysis/resynthesis program 'WinPitch' (Martin, 2000), or on 'Praat'.

\section{Results}

\section{Spontaneous speech}

Narrow focus is marked prosodically in both dialects. Algiers variety is characterized by rising falling contours and especially by a final melodic drop. Oran dialect is characterized by a lengthening of stressed syllables with lowered contours which are generally flat. F0 peak alignment is usually on pre-nuclear syllable in Algiers dialect. 


\section{Read speech}

The statement used in read speech is: "Ali (he) is sick." [Gali rah mri:d']; the speakers were asked to vary the type of focus.

It appears from the acoustical analysis that recurrences of prosodic patterns that differentiate the two dialects were observed in only two types of focus: the emphatic narrow focus when it is at the edge of an intonation phrase and interrogative focus. Emphatic narrow focus is produced in the Algiers dialect by a high and falling contour on the last stressed syllable. In the Oran dialect, this focus is realized either with a contour which is flat or slightly rising on the last stressed syllable (figure 1). In both dialects the stressed syllable is lengthened.

In the interrogative focus Algiers speakers produce an amplified rising-falling contour while Oran speakers produce on the last syllable a rising contour preceded by a falling one (figure 2). The realization of contrastive focus varied across speakers of the same dialect. Broad focus was realized with similar intonation patterns for both dialects.
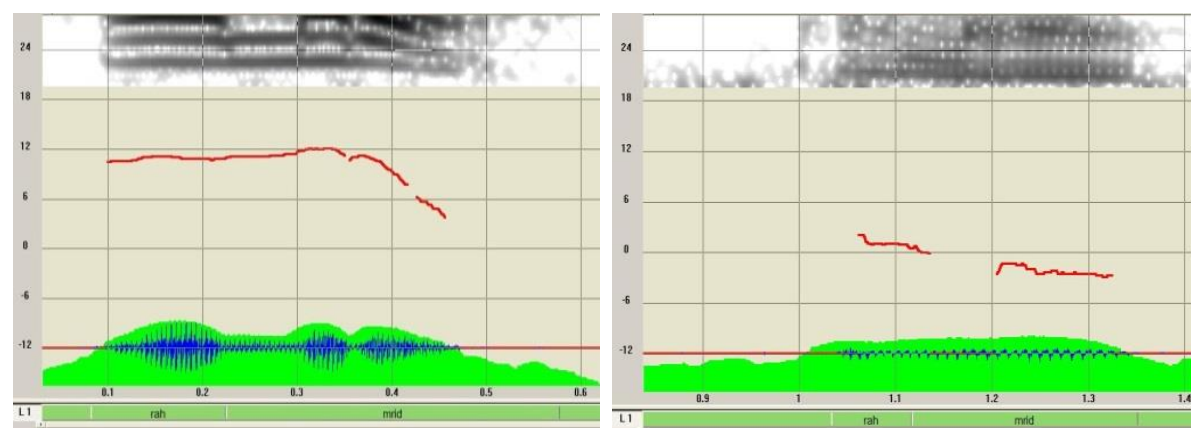

Figure 1. Emphatic narrow focus produced by Algiers (left) and Oran speakers (right).
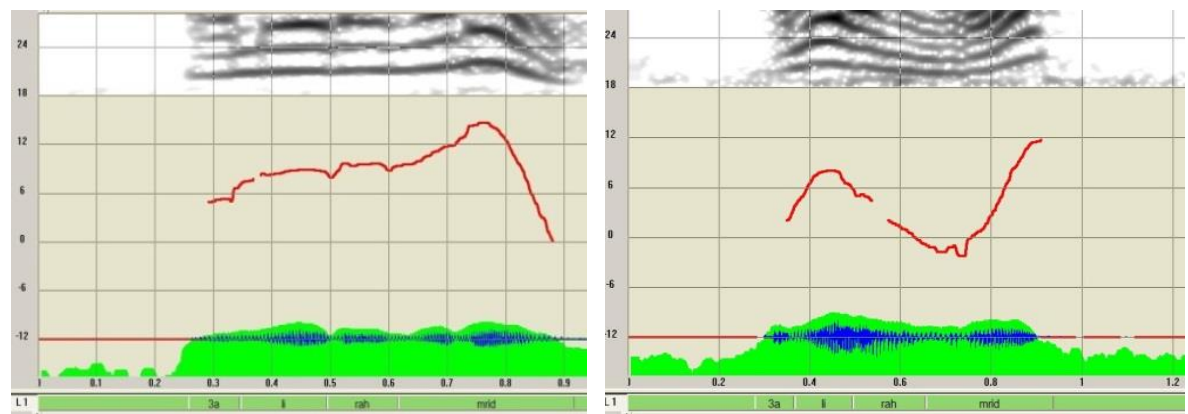

Figure 2. Interrogative focus produced by Algiers (left) and Oran speakers (right).

\section{Perception test results}

The interaction between identification of Algiers and Oran dialects and types of focus is significant: $p<0.0001$ (figure 3). Algiers speakers were clearly identified in all types of focus. Algiers and Oran speakers were 
better identified in interrogative focus (80\%). Only Algiers speakers were better identified in emphatic narrow focus $(90 \%)$ while $53 \%$ of Oran speakers were identified.

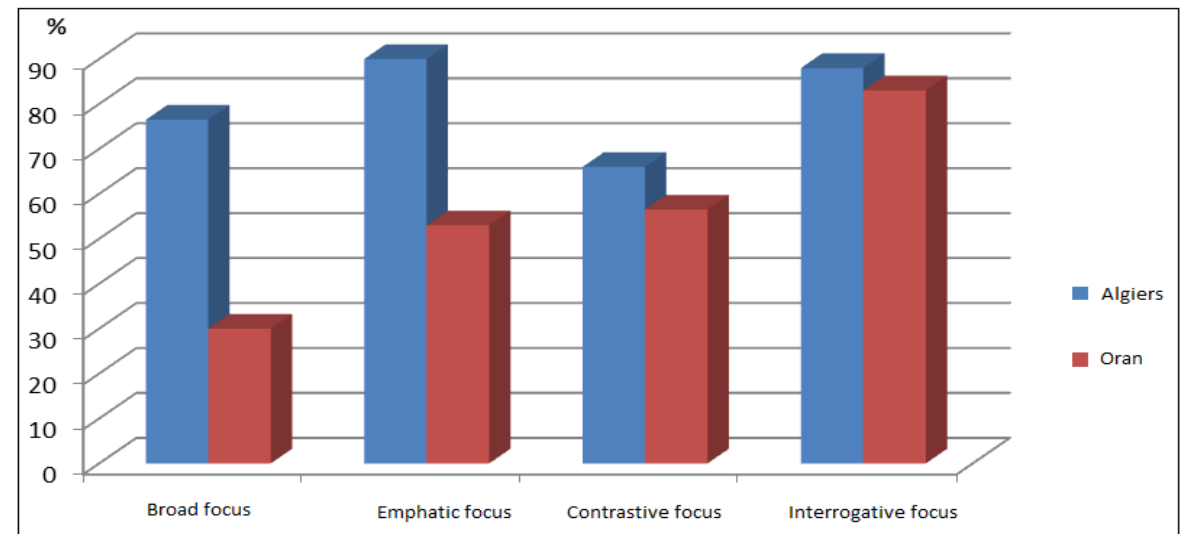

Figure 3 Interaction of identification rate and type of focus

\section{Conclusion}

The narrow emphatic focus and the interrogative focus distinguish Algiers and Oran dialects and they are better identified in these types of focus.

\section{References}

Benali, I. 2004. Le rôle de la prosodie dans l'identification de deux parlers algériens: l'algérois et l'oranais. Workshop MIDL.

Bouchhioua, N. 2009. Stress and Accent in Tunisian Arabic. First International Conference on Intonational Variation in Arabic, 28-29.

Helimuth, S. 2011. Acoustic cues to focus and givenness in Egyptian Arabic. Instrumental Studies in Arabic Phonetics, 319, 301.

Hirst, D., Di Cristo, A. 1998. Intonation systems: a survey of twenty languages, Cambridge University Press.

Martin, Ph. WinPitch 2000: a tool for experimental phonology and intonation research. Proceedings of the Prosody 2000 Workshop, 2000.

Yeou, M., Embarki, M., Al-Maqtari, S. 2007. Contrastive focus and F0 patterns in three Arabic dialects. Nouveaux cabiers de linguistique française, 317. 